\title{
ROCK MAGNETISM
}

$\mathrm{A}^{\mathrm{T}}$

T a meeting of Section A of the British Association on September 4, Prof. P. M. S. Blackett opened a discussion on "Rock Magnetism" by giving a brief account of the history and the present state of the subject. He pointed out that although it has been known for the past hundred years that certain rocks, when formed, acquire a weak but definite magnetism in the direction of the Earth's field, it is only recently that this fact has been used for deducing two types of information of the highest scientific importance : first, to trace back for many millions of years the history of the direction and intensity of the geomagnetic field; and secondly, to attempt to settle the old and acute controversy as to whether the continents have always occupied the same positions relative to one another and to the geographical poles.

Discussing the first of these two aspects of palæomagnetism, Prof. Blackett said that his interest in the subject was originally aroused by the work of Johnson, Murphy and Torreson ${ }^{1}$ in the United States, who, in 1948, examined the remanent magnetization of a series of varved clays of New England. These clays were laid down in stream beds, and contain small quantities of detrital magnetic material in the form of fine grains, which were oriented along the Earth's magnetic field at the time of deposition. By measuring changes in the direction and intensity of magnetization with depth, over a continuous vertical sequence, it was possible to trace the history of the geomagnetic field over a period extending back to 15,000 B.c. The results showed that during the whole of this time it has undergone regular variations in direction about geographic north. More recent investigations have confirmed this view, and it now appears that for at least several million years the main Earth's field has corresponded on the average to that which would be produced by an axial magnetic dipole situated at the centre of the Earth; but that there has been a continuous secular variation about the mean direction, with a time period of $500-1,000$ years.

Of the greatest importance was the discovery by Brunhes $^{2}$ in 1906 that certain lavas from the Massif Central mountain system in France are magnetized in a direction opposite to that of the Earth's field. Many other examples of reverse magnetization in Tertiary igneous rocks have since been discovered, notably by Bruckshaw and Robertson ${ }^{3}$ in Britain, by Roche $e^{4}$ in France, and by Hospers ${ }^{5}$ in Iceland, and more recently by Campbell and Runcorn (unpublished work) in America. All these workers found that while approximately half the rocks sampled had an average palæomagnetic direction corresponding closely to that of an axial dipole, the remaining half were magnetized in the opposite direction. Roche and Hospers, in particular, considered that their findings could be most plausibly interpreted on the assumption that the Earth's main field has reversed periodically during Tertiary and recent times. They suggested that these reversals must have occurred rather suddenly at intervals of the order of a million years, and that the field intensity in both the opposite directions has been the same. This result, if true, is of extreme importance, and must dominate all future theoretical thinking on the origin of the Earth's magnetism. Many geophysicists, however, regard the hypothesis of the Earth's field reversal with reserve, and $\mathrm{Né}^{6}{ }^{6}$ has put forward theoretical arguments to show that there are four possible physical mechanisms whereby a rock, in cooling from above its Curie temperature, can acquire a thermo-remanent magnetization in a direction opposite to that of the applied field. The first two of these mechanisms depend on the properties of ferrimagnetic materials, in which the magnetism is associated with two distinct categories of electron, the spins of which are aligned in antiparallel directions. Gorter ${ }^{7}$ has recently succeeded in synthesizing a ferrimagnetic material which exhibits magnetic self-reversal in the laboratory, and there is no reason for supposing that such a material may not have been produced naturally in certain rocks. The third and fourth of Néel's mechanisms are based on the supposition that the rock contains two distinct magnetic components with different Curie points, which exist as an intimate mixture of fine grains. When such a rock cools, it is possible in certain circumstances for one component to become magnetized in the reverse field of the other, and for the final direction of magnetization to be opposite to that of the externally applied field. One example of a naturally occurring rock, which exhibits a self-reversing property of this kind in the laboratory, has been found by Nagata ${ }^{8}$. On the other hand, the great majority of reversely magnetized rocks do not exhibit any self-reversing property when tested in the laboratory.

Considering the whole of the evidence at present available, Prof. Blackett thought that while it is very probable that the Earth's field has reversed periodically in the past, this must not be taken as being finally proved.

Turning to the geological aspects of palæomagnetism, Prof. Blackett said that it was realized at least thirty years ago that, by the study of magnetism of rocks, it should be possible to discover whether there has been any relative movement between the continents during past geological ages, as suggested by Wegener $^{9}$, du Toit ${ }^{10}$ and others. For, by measuring the present direction of magnetization of a system of rocks, it is possible to deduce both the latitude and the orientation relative to the Earth's rotational axis at the time when it was laid down.

The first palæomagnetic evidence of past continental land movement was obtained in 1954 by Clegg, Almond and Stubbs ${ }^{11}$, who found rocks of the New Red Sandstone system, over a wide area of England, to be consistently magnetized along a north-east to south-west axis with magnetic dips considerably shallower than that of the present Earth's field. This suggests that England has moved northwards from a position near the equator, and has rotated in a clockwise sense relative to the poles, at some time since the rocks were formed about 150 million years ago. During the past two years, there have been many more startling results from various parts of the world. It now looks as though the land masses of the northern hemisphere have moved collectively some $40^{\circ}$ northward from the equator, while both India and South Africa appear to have been much nearer to the South Pole several hundred million years ago. 
These substantial changes in latitude may have been attended by a relative drift between the continents as required by the continental drift hypothesis, or they may represent a movement of the crust as a rigid whole across the poles--often called polar wandering. At present it seems as though relative drift has occurred, but the experimental observations are very incomplete. It should be possible, by piecing together evidence from rocks of all ages and lands, to resolve this question during the next few years.

Dr. A. E. M. Nairn gave an account of the work carried out by members of the group working for the past five years under Prof. S. K. Runcorn, first at Cambridge and later at King's College, Newcastle upon Tyne. Rocks have been collected from almost every geological formation in Great Britain, and from many formations in North America, Europe and South Africa.

Speaking of the evidence for polar wandering and continental drift, Dr. Nairn said that the results of palæomagnetic measurements on rocks of a particular locality and geological period are best expressed in terms of the pole position, which is calculated on the assumption that the direction of magnetization corresponds on the average to that of the axial dipole field at the time of deposition. The pole position obtained in this way represents the mean of many measurements, and its reliability can be expressed in terms of a 'circle of confidence', which is a statistical measure of the dispersion of the results. For a particular rock formation, the dispersion depends on the origin and geological history of the rocks, and it has been found to be least for red sandstones and basic extrusive rocks, so that on the whole the work has tended to be concentrated on these lithological types. Since red sandstones and basic extrusions are rare in the Jurassic, Cretaceous and Ordovician systems, in the northern hemisphere, these periods have not been so well studied as others. From extensive observations accumulated from palæomagnetic measurements in Britain, dating back to the Precambrian, Creer ${ }^{12}$ assembled the pole positions in chronological order, and plotted them on a polar projection. He showed that the points can be joined into a continuous curve. Later, Runcorn ${ }^{13}$ was able to produce a similar curve based on his and Du Bois's results from North America, which, although similar in form, showed a systematic displacement, the pole positions as calculated from the American measurements lying consistently to the west of the British. Further work has tended to confirm the existence of this discrepancy between the two curves, and there is now strong evidence for the supposition that the American continent has drifted about 2,000 miles westward relative to Europe. This drift seems to have occurred since the late Triassic period, and to have been completed before the end of the Miocene. The extension of the work to continents other than Europe and North America is generally handicapped by the imperfectly known geology; but a series of samples have been obtained from Kenya, Bechuanaland and Rhodesia. These all belong to the Karroo system, which extends in time from the Upper Carboniferous to the Lower Jurassic. The collection of reliable material from surface exposures in this part of the world is rendered difficult by the very deep weathering that has occurred, and the only satisfactory result available so far has been obtained from the Lower Jurassic basalts of the Victoria Falls area. The measurements made on these rocks suggest that the African continent has moved some 2,000 miles with respect to the poles since they were laid down.

The value of an independent check on this palæomagnetic evidence for past continental land movements is obvious, and there are, in the geological record, a number of phenomena such as the occurrence of coal facies, desert sands and red beds, salt deposits, ice ages and tree rings, which depend on climatic conditions, and which can be used for this purpose. The most reliable palæoclimatic data available at present are those obtained from fossil wind directions, which can be found by examination of dune bedding in ancient deserts; for, since the directions of the trade winds are controlled by the Earth's rotation, it is unlikely that their directions could have changed radically during the Earth's history. The subject of fossil winds is being studied at present by N. D. Opdyke at Newcastle upon Tyne and by workers in the United States, and preliminary results for a number of geological periods appear to confirm the pole positions traced for the same epochs from rock magnetic measurements. However, all palæoclimatological evidence does not support the palæomagnetic findings. On $\Theta$ particular problem still unsolved concerns the palæomagnetic pole position during the Permo-Carboniferous period, which is situated in China, where, according to palæobotanical evidence, warm conditions prevailed at that time.

Discussing the question of reversals of the Earth's field, Dr. Nairn considered the best evidence of past reversals to $b_{\theta}$ found in the work of Hospers ${ }^{5}$, mentioned previously, and that of Irving ${ }^{14}$ on the Torridonian sandstones of Scotland.

Dr. J. A. Clegg described palæomagnetic research carried out at the Imperial College of Science and Technology in London, and elsewhere. Discussing the subject of continental drift, he first compared the original measurements made by Clegg, Almond and Stubbs ${ }^{11}$ on the British Triassic sandstones, which had been described earlier by Prof. Blackett, with more recent results obtained by Graham $^{15}$ for similar Permian and Triassic sandstones in the western United States. The mean directions of magnetization of the British and American rocks correspond respectively to pole positions $155^{\circ} \mathrm{E}$., $48^{\circ} \mathrm{N}$., and $106^{\circ} \mathrm{E}, 34^{\circ} \mathrm{N}$, both lying in eastern Asia. It appears, therefore, that there has been a considerable change in the positions of both these land areas relative to the Earth's rotational axis since Triassic times. The two positions lie approximately $20^{\circ}$ apart, and this suggests that there may also have been a relative movement between Britain and North America ; but the dispersion of the results and the uncertainties in dating are such that there is grave doubt as to the significance of this discrepancy. After mentioning measurements by Gough ${ }^{16}$ on the Pilansberg dyke system of Africa, which indicate that South Africa probably occupied a position on the other side of the south pole some 250 million years ago, Dr. Clegg went on to describe some more recent work being carried out at present by the Imperial College group on lavas of the Deccan Trap system of India ${ }^{17}$. These latter rocks are found to have consistent directions of magnetization corresponding to a position of the north geographical pole close to Florida $\left(85^{\circ} \mathrm{W} .2^{\circ} \mathrm{N}\right.$.), which implies that at the time when they were laid down, some 70-100 million years ago, the Indian subcontinent must have been situated considerably to the south 
of the equator. This result is supported by palæoclimatic evidence, for it is well known that during the Permo-Carboniferous period there was heavy glaciation in India, and that the ice was flowing northward.

The Imperial College group has also made palæomagnetic measurements, in collaboration with Prof. J. C. Jaeger at Canberra, on certain Tasmanian Jurassic-Cretaceous dolerites, 100-120 million years old, together with overlying Tertiary basalts. The samples were taken from unoriented diamond-drill cores, so that it was not possible to measure the azimuthal direction of magnetization. However, the magnetic dips proved to be much steeper than that of the present dipole field in Tasmania, the mean directions of magnetization of the dolerites and basalts lying respectively within $5^{\circ}$ and $7^{\circ}$ of the vertical. This means that some 100 million years ago Tasmania was within $10^{\circ}$ of the south pole, and that its latitude remained substantially unchanged at least until early Tertiary times. It is interesting to compare this result with that previously quoted for the Indian rocks of similar age. For, expressed in terms of pole position, it places the north pole close to a point antipodal to Tasmania in the western North Atlantic, at least 2,500 miles from the position obtained for the Deccan Trap measurements. This seems to supply good presumptive evidence of a relative movement between Tasmania and India.

Finally, Dr. Clegg described two experiments carried out on reversely magnetized rocks. The first was concerned with a volcanic tuff from Tasmania, obtained from the same borings as the basalts and the dolerites mentioned previously, but from a greater depth. A single five-foot length of core was examined, and was found to be magnetized, like the overlying dolerite, in an almost vertical direction; but whereas over the major part of its length the magnetic dip was in a normal (upwards) sense, over a single fiveinch portion the polarization was reversed. The reversed and normal portions appear to be identical in all respects, and so far no satisfactory explanation of the phenomenon has been found. The result does, however, serve to emphasize the complexity of the problem of interpreting magnetic reversals. The second experiment was carried out by J. Fi. Leng on three 'Tertiary dykes from Arran. Two of these dykes, together with the baked sediments in contact with them, were uniformly magnetized in directions close to that of the present Earth's field; but in the third case, both the dyke rocks and the contact sediments had acquired a thermo-remanent magnetization in the reverse direction. Since the magnetic minerals present in the igneous intrusion are very different from those in the surrounding country rocks, it seems unlikely that this reversal of both dyke and contact sediments can be due to a Néel effect. Experiments of this type would appear to provide strong evidence for the hypothesis of the reversal of the Earth's field.

All the speakers emphasized at the meeting their belief that while information of great importance has already been obtained from palæomagnetic studies, the present conclusions must be regarded as purely tentative, and will be subject to continuous modification as the work develops.

J. A. ClegG

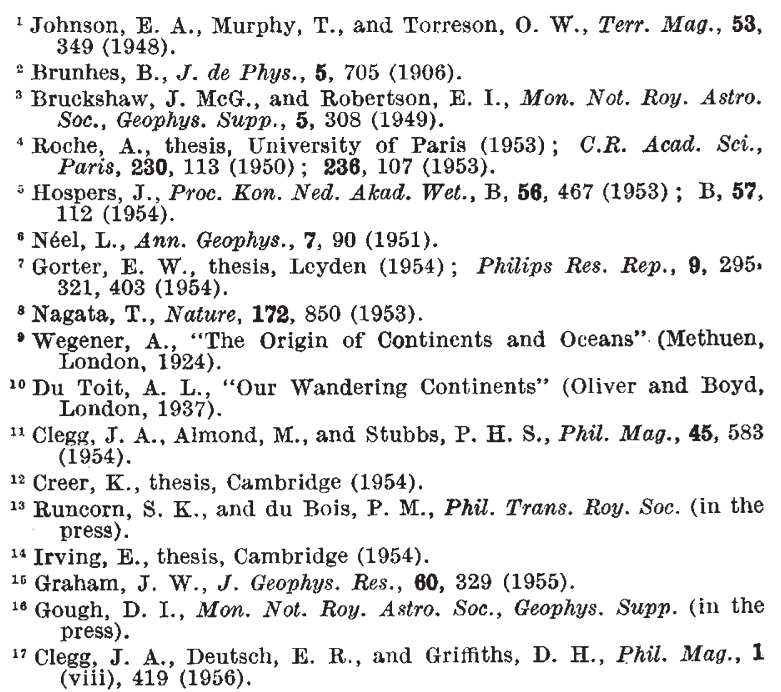

\section{THE CHEMICAL RESEARCH LABORATORY}

THE annual open days of the Chemical Research Laboratory (Department of Scientific and Industrial Research) were held during October 2-5. Some of the exhibits by the six main research groups are described in the following paragraphs.

One laboratory has been reconstructed to house the larger apparatus used in corrosion research. A preparation room is equipped for the surface preparation of specimens, maintenance of testing equipment, and water treatment. A constanttemperature room, of brick and glass-brick construction with double glazing on the windows, is provided with humidity control. Four model boilers, each with six electrically heated tubes giving a heattransfer rate of 7,000 B.Th.U./59 sq. ft. of tube surface per hour, are used in an investigation on behalf of the British Shipbuilding Research Association. A circulation apparatus for studying corrosion and its prevention in flowing water was in operation. The test solution is pumped from a tank into a header tank and runs back into the lower tank through the test specimens, which are in the form of mild-steel tubes. Non-corrodible stoneware pumps and glass tanks are used, so that the only metal in the circuit is the material under test.

Goods are often protected during storage and transit by enclosure in impervious wrappings. Although such wrappings prevent the entry of corrosive agents from outside, they may aggravate corrosion of the metallic contents by accumulation of relatively reactive compounds evolved from nonmetallic components. At the lsaboratory, corrosion in radio receivers has been traced to vapours evolved from synthetic resins and glues. Exploratory studies are being made of the corrosive effect of some likely 